\title{
Adapting to Climate Change: Social-Ecological Resilience in a Canadian Western Arctic Community
}

\author{
Fikret Berkes and Dyanna Jolly
}

ABSTRACT. Human adaptation remains an insufficiently studied part of the subject of climate change. This paper examines the questions of adaptation and change in terms of social-ecological resilience using lessons from a place-specific case study. The Inuvialuit people of the small community of Sachs Harbour in Canada's western Arctic have been tracking climate change throughout the 1990s. We analyze the adaptive capacity of this community to deal with climate change. Short-term responses to changes in land-based activities, which are identified as coping mechanisms, are one component of this adaptive capacity. The second component is related to cultural and ecological adaptations of the Inuvialuit for life in a highly variable and uncertain environment; these represent long-term adaptive strategies. These two types of strategies are, in fact, on a continuum in space and time. This study suggests new ways in which theory and practice can be combined by showing how societies may adapt to climate change at multiple scales. Switching species and adjusting the "where, when, and how" of hunting are examples of shorter-term responses. On the other hand, adaptations such as flexibility in seasonal hunting patterns, traditional knowledge that allows the community to diversity hunting activities, networks for sharing food and other resources, and intercommunity trade are longer-term, culturally ingrained mechanisms. Individuals, households, and the community as a whole also provide feedback on their responses to change. Newly developing co-management institutions create additional linkages for feedback across different levels, enhancing the capacity for learning and self-organization of the local inhabitants and making it possible for them to transmit community concerns to regional, national, and international levels.

\section{INTRODUCTION}

The debate on climate change has only recently begun to take into account issues related to human response or adaptation (Smithers and Smit 1997), and the present agenda for research on climate change is still not devoting much attention to the question of adaptation (Wilbanks and Kates 1999). The word "adaptation" figures prominently in the titles of some of the major publications in this area (e.g., Watson et al. 1996), but not in their contents. "There is thus a grave mismatch between the knowledge that is needed to act locally and what is currently being done globally to generate knowledge about climate change, its impacts, and responses to concerns ... "(Wilbanks and Kates 1999:616). Limits to our current levels of adaptation to existing climatic variation are demonstrated by the impacts and costs to society associated with events such as floods, ice storms, droughts, and hurricanes. All societies have to face extreme events, and societies and economies evolve with the fluctuations of their climatic environment. Probably the largest body of literature on how societies deal with climate change is in the fields of history and archaeology (McIntosh et al. 2000).

Although history is instructive, there is also a need to carry out place-specific analyses of adaptation to climate change in the present-day world. This is because the inevitable surprises of climate change will unfold on a regional and local stage where adaptive response becomes central (Holling 1997). Understanding the dynamic interaction between nature and society requires case studies situated in particular places and cultures. The outcomes of stresses such as climate change may be addressed by " ... integrated place-based models that employ semi-quantitative representations of entire classes of dynamic behavior ... " (Friibergh Workshop on Sustainability Science 2000). Research of this type must be created through a process by which researchers and local stakeholders interact to define important questions, relevant 
evidence, and convincing forms of argument (Friibergh Workshop on Sustainability Science 2000).

There are three reasons why the Arctic is one of the best places to study human adaptations to climate change. First, it is expected that the effects of climate change will be felt earlier and more keenly in the polar latitudes than elsewhere in the world. Above-average temperature increases are projected for northwest Canada and Alaska, with high regional variability (Maxwell 1997). The western Arctic rim of North America is the "miner's canary" that exhibits the early warning signs of global climate change. Second, the peoples of the Arctic have always lived with a high degree of environmental variability, and the capacity to adapt to extreme variability is part of Inuit culture (Balikci 1968, Langdon 1995). The "flexibility" of social relations in Inuit culture is often explained by scholars in terms of ecological adaptiveness (Freeman 1996). Third, there has been a growing body of participatory research in the Canadian Arctic since the 1980s, in areas ranging from wildlife co-management to the use of traditional knowledge in environmental assessment (Berkes et al. 2001).

In our previous work, we provided some examples of how communities in the Canadian North were responding to large-scale alterations of the environment, and the ways in which the systems that allow them to make their livelihoods on the land might be vulnerable to change. Their experience indicates that increased variability and the greater frequency of extreme events create adaptation problems because they interfere with the ability of people to access resources on the land, making resource availability itself less predictable (Fast and Berkes 1998). We suggested ways in which traditional knowledge in northern communities might complement our western science-based understanding of climate change in the Arctic, and argued that local observations and knowledge were essential for comprehending the effects of climate change on communities such as Sachs Harbour in the Canadian western Arctic (Riedlinger and Berkes 2001).

In this paper, we analyze the adaptive capacity of the community of Sachs Harbour to deal with climate change. One component of this adaptive capacity is the actual response to change; we identify these responses as coping strategies. A second component is related to Inuit adaptations for life in a highly variable and uncertain environment; these we consider long-term adaptive strategies. We deal with the adaptation of the integrated social-ecological system, and we analyze change through the lens of resilience.

To clarify our terminology, we use the term "adaptive" in the usual evolutionary ecological sense to mean any response that increases a population's probability of survival. We distinguish between coping mechanisms and adaptive strategies in accordance with the terminology commonly used in anthropology (e.g., McCay 1978) and the development literature (Davies 1993, Singh and Titi 1994). Coping mechanisms are the bundle of short-term responses to situations that threaten livelihood systems, and they often take the form of emergency responses in abnormal seasons or years. Adaptive strategies, on the other hand, are the ways in which individuals, households, and communities change their productive activities and modify local rules and institutions to secure livelihoods. The two kinds of responses may overlap across the temporal scale, and coping mechanisms may develop into adaptive strategies over time. Coping mechanisms are more likely to emerge at the level of the individual and the household and at smaller spatial scales, whereas adaptive strategies, which are related to variables such as cultural values that change more slowly, are more likely to emerge at larger spatial scales. Explicit attention to these two kinds of responses helps highlight the multiscale nature of the problem of change.

The scope of our study is the response related to the land-based activities of the people of Sachs Harbour, who live in a mixed economy (wage income, transfer payments, and subsistence harvesting) and who have continued to obtain much of their protein from hunting and fishing activities, as do many communities in the Canadian North (Berkes and Fast 1996). This focus on land-based activities makes good analytical use of the integrated concept of humans-in-nature or the socialecological system as defined by Berkes and Folke (1998). Note that we are not focusing exclusively on environmental change or on social change, but rather on changes in the social-ecological system.

We assess change in terms of the organizing concept of resilience, which has three defining characteristics. It is a measure of (1) the amount of change the system can undergo and still retain the same controls on function and structure, (2) the degree to which the system is capable of self-organization, and (3) the community's ability to build and increase its capacity 
for learning and adaptation (Resilience Alliance 2001). The terms "self-organization," "learning," and "adaptation," which are important for our arguments, are those defined by the Resilience Alliance (www.resalliance.org). Although the concept of resilience is most commonly used in the study of ecosystem dynamics (Holling 1973), it can also be applied to social systems (Adger 2000, Adger et al. 2001), social-ecological systems (Gunderson et al. 1995, Berkes and Folke 1998, Gunderson and Holling 2001), and the study of global change (Holling 1997).

In this paper, we first illustrate a method of carrying out place- and culture-specific research into climate change by means of participatory methodologies and a way of using resilience thinking to explore the issue of adaptation to climate change. We investigate how human societies deal with change in social-ecological systems, and we also seek to generate insights for the use of coping strategies and available adaptive strategies to build the capacity to adapt to change. To address these questions, we use the place-specific case of climate change in an Arctic community.

\section{A MODEL OF A COMMUNITY RESEARCH PARTNERSHIP}

This paper is based on "Inuit Observations of Climate Change," a collaborative project carried out by the Inuvialuit people of Sachs Harbour and the International Institute for Sustainable Development (IISD). The project setting was the community of Sachs Harbour on Banks Island in the Canadian western Arctic. Sachs Harbour is the smallest of the six Inuvialuit (western Arctic Inuit) communities in the region covered by a comprehensive land claims agreement, the Inuvialuit Final Agreement, also known as the Inuvialuit Final Agreement of 1984 (Fast et al. 2000). Sachs Harbour, which has been a permanent settlement since only 1956, is an outgrowth of the white fox trade that began in the 1920s. The current residents are descendants of the Mackenzie Delta people to the south, the Inupiat (Alaska Inuit) to the west, and the Copper Eskimo of Victoria Island to the east (Usher 1970).

The project's objectives were to produce a video on how climate change is affecting Sachs Harbour residents, to educate southern Canadians and decision makers regarding climate change, to document Inuvialuit knowledge of climate change, and to explore the potential contributions of traditional knowledge to climate change research (Ford 1999, Riedlinger 1999).

The results are based on a study of Sachs Harbour that covered all four seasons during a 12-month cycle in 1999-2000, plus a follow-up visit for verification and project evaluation. The larger project team included the organizers from the IISD, a film crew that documented Inuvialuit perspectives on video, technical experts who conducted science interviews on the more specialized areas of change (e.g., sea ice, permafrost geology, and terrestrial wildlife), local experts and liaison people from the Inuvialuit region (including the project's scientific coordinator), and a university team. The university team was responsible for leading the traditional knowledge component of the study, arranging follow-up visits by the project team, conducting longer-term field work in the community, and providing documentation.

The project was initiated by Sachs Harbour, a tiny community of some 30 households, through their representative, who had served as a national leader for the Canadian Inuit. A total of 13 households participated directly throughout the project by taking part in its main components (the planning workshop, the video, and the science interviews) and by guiding project team members on the land; many other local people participated indirectly. The 13 households represent the full population, not just a sample, of elders and hunters whose families are active harvesters who spend significant amounts of time on the land. The Sachs Harbour residents involved in the study were those considered by the rest of the community to be the local experts on climate-related change.

The project design was based on participatory methodologies that were intended to facilitate collaboration and provide the most accurate reflection of Inuvialuit observations and perspectives (Ford 1999). The methods used drew on a series of techniques developed by the project leader based on the ZOPP (Ziel Orientierte Projekt Planung, or Objectives Oriented Planning) approach, in addition to established approaches such as Participatory Rural Appraisal (Ford 1999). The research process was inclusive, i.e., open to participation by all; all the elders were included, and gender representation was balanced.

One of the key features of the project was the initial planning workshop, in which the people of Sachs 
Harbour were asked to tell the researchers what they considered important. The priority issues, research questions, plans for the video, and the overall process for the project were defined in partnership by the project personnel and the community. The climate change video, a main output of the project, was also used for community feedback and for the verification of findings. Interviews allowed people to explain their more detailed observations and to interact with western scientists with expertise in specific areas (Ford 1999).

Considering the project as a model research partnership, some of its most relevant features were the planning workshop; repeat visits to the community that focused on activities appropriate for that season; the reporting of the results back to the community in the form of videos, trip reports, and newsletters; and the continuity provided by two members of the team who took part in all four trips and stayed for longer periods. Information was collected using a variety of interlinked participatory methodologies: brainstorming workshops, focus groups, video interviews, and individual semidirective interviews. Also used was participant observation, a very important methodology from the point of view of the Sachs Harbour Inuvialuit because "going on the land" is how people are supposed to learn about the environment.

\section{CHANGES AND THE ANNUAL HARVESTING CYCLE}

The observations of Sachs Harbour hunters and elders were remarkably consistent in providing tangible evidence of climate change. The changes observed in the 1990s were said to be without precedent and outside the range of variation that the Inuvialuit consider normal. The changes reported involved the extent of sea ice, the timing and intensity of weather events, fish and wildlife distribution, permafrost depth, and soil erosion. A summary of these changes and their impacts on land-based activities may be found in Table 1. More detailed results of the community's observations of climate change have been reported elsewhere (Ford 1999, Riedlinger 1999, Riedlinger and Berkes 2001), and captured on the video "Sila Alangotok: Inuit Observations of Climate Change." The short version of the video is available through the IISD Web site.

Table 2 shows the results of a survey carried out near the end of the project to verify that the observations reported on the video and in the project reports did indeed represent community consensus. The survey was administered verbally by the community fieldworker to 12 of the 13 households that participated directly in the project, plus 5 households that did not; the latter were included to obtain a wider range of views from the community. The results indicate near-unanimous views on the reported changes. For example, the one informant who did not think that the video accurately reflected the changes they were observing commented that the video captured "only some of it."

These observations indicate an increase in variability in the climate that is causing the environment to become increasingly unpredictable. According to the Inuvialuit, these observed changes are having an impact on hunting, fishing, and other subsistence activities as well as on guiding sport hunters and traveling on the land. In fact, Sachs Harbour is not unique in this regard. Several communities in the Canadian Arctic and Alaska have been reporting environmental changes different from normal variability (Fisheries Joint Management Committee 1999, Riedlinger and Berkes 2001).

To provide context, we reviewed the annual cycle of harvesting activity at Sachs Harbour. Some 20 species of terrestrial and marine mammals, fish, and birds are taken throughout the year. Of these, the main species is musk-ox (Ovibos moschatus); others include the lesser snow goose (Anser caerulescens), the ringed seal (Phoca hispida), and various fish species. During the winter, people hunt musk-ox and, to a lesser extent, caribou (Rangifer tarandus), Arctic foxes (Alopex lagopus), wolves (Canis lupus), polar bears (Ursus maritimus), and ringed seals. The island supports a large population of musk-ox that has increased since the 1950s (Gunn et al. 1991, Nagy et al. 2001). Small game includes ptarmigan (Lagopus spp.) and Arctic hare (Lepus arcticus). In the past, winter was the season for Arctic fox trapping, which was a mainstay of the local economy until the European fur ban of the 1980s.

As the weather begins to warm in March and April, people head out to numerous inland lakes to ice fish for lake trout (Salvelinus namaycush) and Arctic char (Salvelinus alpinus). In May, fishing slows down as the snow goose hunting season approaches. Banks Island supports a large breeding colony of snow geese. Goose hunting, along with collecting goose eggs, is one of the most important community activities. 
Families camp at rivers and inland lakes, and the entire community is busy hunting, plucking, cleaning, and drying geese; some of the resulting products are intended for intercommunity trade.

Table 1. Examples of local environmental changes and effects on subsistence activity described by the community of Sachs Harbour.

Impacts Comments

Access

Safety

Predictability

Species availability
Old ice doesn't come in close to the settlement in summer anymore, more difficult to hunt seals

Less ice in summer means that the water is rougher

Open water is closer now in winter, cannot go out as far when hunting

More rain in summer and fall, makes it difficult to travel

Water and puddles on the ground that don't dry up in summer

Rough on the land to travel now; have to make new trails

Snow is not hard packed like before; more loose, soft snow, harder to travel

Difficult to hunt geese in the spring because it melts so fast

It is easier to travel in winter now that it is not so cold

Too much broken ice in winter makes travel dangerous

Unpredictable ice conditions make travel dangerous

Less multiyear ice in fall at freeze up means we have to travel on first year ice all

winter, less safe

Less ice means you have to worry about storms now

More difficult to know when the rivers will break in the spring

Harder to predict when there is going to be a storm

Spring season is more variable, from year to year the arrival of spring is different

'Wrong' winds sometimes now, stronger, changing directions

More bad weather with blowing snow and whiteouts; hard to travel

More overcast days, strange weather

More rain in the fall increases chances of freezing rain, which can lead to caribou starving

Warmer summers and more rain mean more vegetation; good for animals

Seeing different species of fish and birds

Less summer ice means less seals around to hunt

Seeing less polar bears in the fall because of lack of ice

One fishing lake drained away into the ocean from slumping and erosion

More least cisco (locally called "herring") caught now

More wind means caribou do not have to travel as far to escape bugs
The goose hunt is over by mid-June, and people return to the lakes to fish if there is still ice. They will also fish for Arctic cod (Boreogadus saida) on sea ice and begin hunting seals. With the advent of summer and the breakup of the ice in June and July, people hunt mainly for ringed seals and some bearded seals (Eringnathus barbatus) off the ice floes and from boats in open water. From July through early September, people set gillnets for char, Arctic cod, and least cisco (Coregonus sardinella). There is some rod- 
and-reel fishing in lakes as well. In September, people turn to musk-ox and caribou hunting again. The peak of the musk-ox hunt is in November. In some years, the musk-ox hunt is a commercial harvest that employs almost the entire community, plus some outsiders, for much of November.

Table 2. Community responses to the Inuit Observations of Climate Change project and project outputs. The "yes" response includes positive comments; the "no" response includes negative comments; and "N/A" includes those who said that the question was not applicable to them or left the question blank. $\mathrm{N}=17$ households.

Question

Yes No N/A

Did you have a say on how the project was organized?

Does the video accurately portray the community?

Does the video accurately reflect the changes you are seeing?

Did you have an opportunity to comment on or correct the information in the video?

Do you think this video can help explain your views to the people in the South about change?

Did the science interviews allow you to express your observations and knowledge of climate change?
13

1322

$15 \quad 1 \quad 1$

$14 \quad 1 \quad 2$

$13 \quad 3 \quad 1$

$17 \quad 0 \quad 0$

$14 \quad 0 \quad 3$

The actual annual cycle of harvesting activity differs from year to year. Probably no two years are alike in terms of harvesting success. Some data on harvest numbers are available from the Inuvialuit Harvest Study, but these statistics are often incomplete, and the numbers hide the complexity of year-to-year variations. Langdon (1995) refers to the "extraordinary range" of annual harvest levels in the Inupiat communities of northern Alaska, in which anomalies (extremely high or low levels of harvest) occurred for one resource species, on the average, every year. Such variations may characterize the harvests of Inuvialuit communities as well.

\section{PROBLEMS AND OPPORTUNITIES RELATED TO CLIMATE CHANGE}

Problems and opportunities related to climate change need to be considered against a background of a highly variable Arctic ecosystem and an equally variable social-ecological system of harvesting activities. The impacts observed by the people of Sachs Harbour may be divided into these groupings: access to resources, safety, predictability, and species availability (Table $1)$.
Access to resources is often related to the ability to travel on land or sea ice. For example, changes in the rate of spring melt and the increased variability associated with spring weather conditions can affect community access to hunting and fishing camps. In May, families go out to camps at lakes for ice fishing and the spring goose hunt. They travel by snowmobile, pulling a qamutik (sled), staying on snow-covered areas, and often using the coastal sea ice and frozen rivers to gain access to the camps. However, warmer springs have resulted in earlier, faster snow melt and breakup of the river ice, making access to camps difficult and shortening the length of time people are able to spend out on the land. In some areas, increased snowfall and deeper, softer snow make it more difficult to travel than on hard, packed snow.

The second theme, safety, comes up most frequently in conversations about the sea ice environment. The sea ice in the vicinity of the community is used for travel, ice fishing, and hunting seal and polar bear. The condition of the ice, the distribution of the ice floes, the location of the floe edge, and the timing of freezeup and breakup events are monitored from both kitchen windows and the ice itself. Weekly flights into 
the community are used as a source of information about ice conditions on a larger scale. Sound knowledge of the sea ice is critical to hunting success and safety, and daily observations are embedded in an understanding of past events. In recent years, it has been noted that ice conditions are less reliable than they were in the past. In the 1990s, people in Sachs Harbour observed more ice movement in winter and spring, overall thinning, and changes in the distribution of leads, cracks, and pressure ridges in the ice. People say that, in the past, they rarely had to worry about the ice the way they do now, but "now you really have to watch" when you travel on the ice.

The safety theme is often linked to predictability. The Inuvialuit rely on their ability to predict phenomena such as snow and ice conditions, the weather, and the timing of wildlife migrations. All of these phenomena have become more unpredictable. Many of the local residents were of the opinion that weather patterns and events were happening "at the wrong time now." For example, as one elder pointed out, weather changes have become more frequent.

"The weather never changed that much years ago ... it was always cold. Not like today. You can't even tell when the weather is going to change. Years ago we knew when the weather was going to change-mild weather meant a storm was going to come, and so we would get ready for it. But today it changes so much; we can be expecting a big storm-next day it is clear as can be. I can't predict the weather anymore like we used to years ago. I used to predict weather when I could see it-it's coming ..." (P. Esau, personal communication).

The fourth group of impacts on subsistence activity involves species availability. Indirect effects of climate change, such as changes to the availability of forage and water or the intensity of parasitic infections, may have an impact on Arctic wildlife, and thus on the community harvest. For example, although warmer temperatures and higher amounts of rainfall have increased the availability of summer forage for caribou and musk-ox, they have also increased the risk of extreme events such as freezing rain that covers the ground with a layer of ice, which makes forage unavailable in the autumn. The availability of some species may change not only because of environmental impacts on the species itself but also because people are forced to hunt them under changing environmental conditions. For example, less summer ice means that ring seals will be harder to spot and hunt. The distribution, abundance, and movement of the species in the region may change as new species appear or established ones, e.g., caribou, change the timing of their migrations (Babaluk et al. 2000).

\section{RESPONDING TO CHANGE: COPING MECHANISMS}

The climate-related changes experienced by the community of Sachs Harbour are relatively recent. Although these changes are affecting subsistence activities, many of the impacts have been absorbed thanks to the flexibility of the seasonal cycle and the Inuvialuit way of life. For the most part, Inuvialuit coping strategies relate to adjusting or modifying subsistence activity patterns, i.e., changing when, where, or how hunting and fishing occur. They also harvest a mix of different species and try to minimize risk and uncertainty.

Increased seasonal variability is causing hunters to adjust the timing of their seasonal calendar. For example, warmer temperatures and unpredictable ice conditions, as described by local experts, have resulted in hunters going out earlier for polar bear. In response to shorter, warmer springs and increased rates of snow and ice melt, people say that they do not go out on the land in the spring for as long as they used to. They return to the community after the goose hunt, rather than proceeding to the lakes to ice fish. Waiting is a coping strategy; people wait for the geese to arrive, for the land to dry, for the weather to improve, or for the rain to end.

Because of erosion and slumping at one nearby fishing lake, the community has begun fishing at other lakes instead. More bare ground and unreliable snow conditions mean that families are traveling along the coastal sea ice rather than along inland routes. Recent changes to the sea ice have meant that hunters now stay close to the community because of safety concerns, while the animals they seek remain farther out. Permafrost thaw in many areas has forced travelers to make new trails and routes to avoid slumps, mudslides, and erosion. Community members describe using all-terrain vehicles instead of snowmobiles to travel to spring camps when there is not enough snow. They also describe hunting seals from boats in the open water, an adjustment necessitated by the lack of ice floes, where the seals normally spend the summer months. 
The community reports that it is catching more qaaqtaq (least cisco) in nets at the mouth of the Sachs River. Because of the lack of open water and bare ground in the spring of 2000, the geese arrived late and laid fewer eggs, and the community collected almost none of them. Pintail ducks (Anas acuta) and mallard ducks (A. platyrhynchos), which are considered mainland ducks, have been observed in the area, and there are higher numbers of white-fronted goose or yellow legs (Anser albifrons) and tundra swans (Cygnus columbianus), birds that have not been abundant on Banks Island in the past.

In response to the increased variability and unpredictability associated with the weather and other environmental phenomena, the Inuvialuit feel a need to monitor conditions more closely, e.g., in rivers in the spring. There is a heightened risk of getting caught on the far side of the river because it is more difficult to tell when the ice will break. People indicate that "... you really need to have experience to travel on the sea ice now ... " and describe being more careful when they travel.

The Inuvialuit of Sachs Harbour draw on their accumulated knowledge base and experience to come up with these coping strategies. They state quite clearly that they have always adjusted and adapted to change: social, political, and economic as well as environmental. People may now use all-terrain vehicles more than dog teams, but as one man said, “ ... it is pretty well the same, how we do things ... " (J. Lucas Sr., personal communication). When asked about the impact of changes on hunting, trapping, and fishing, most people were quick to point out that they always found some way of getting something. Some people described how, in one sense, it is easier to cope with environmental change now than in the past, because the community does not rely exclusively on local foods. Also, environmental changes are an expected part of the Arctic environment. In the past, severe weather events such as freezing rain could significantly reduce a caribou herd through starvation, leading to severe food shortages for the local people as well. In the contemporary mixed economy, the Inuvialuit have a wider range of food options.

The effects of some changes are more severe than others and require different types of responses. Although this paper focuses on the impacts and adaptations associated with harvest and subsistence activity, climate change may have other economic and cultural consequences as well. For example, whereas recent changes to the sea ice environment have been making travel dangerous and wildlife less accessible, the lack of sea ice also makes some people "lonely for the ice," because the ice is a central feature of Inuvialuit life. Other environmental changes, such as those related to permafrost (e.g., thaw slumps, soil erosion), may not pose a direct threat to the subsistence lifestyle of the Inuvialuit, but do have direct impacts on other aspects of community life, such as the maintenance of buildings and roads.

\section{LONG-TERM RESPONSE OPTIONS: ADAPTIVE STRATEGIES}

The scope and scale of climate change experienced by the community of Sachs Harbour in the 1990s were substantial, but these changes were not beyond the range of the community's ability to respond by adjusting its subsistence activities to accommodate increased seasonal variability. This ability to cope is not unique to Sachs Harbour. As Krupnik (1993:210) notes, "Dynamic and flexible use of the environment constitutes the chief adaptive strategy of Arctic communities." However, the changes observed in Sachs Harbour are recent, and how the community has responded up to now may not be a reliable indication of their ability to adapt in the future.

The adaptive capacity of the Inuvialuit to absorb perturbations will depend in part on their ability to learn and reorganize and in part on culturally available response options. This section addresses the traditional cultural adaptations made by the Inuit (here we use Inuit as the more inclusive term) to deal with environmental variability and uncertainty. The question of whether these strategies are still viable in the contemporary world will be examined in the next section.

Anthropologists and other social scientists (Balikci 1968, Krupnik 1993, Freeman 1996) have identified several clusters of cultural practices that are considered to be adaptive responses to the arctic environment. These include: (1) mobility and flexibility in terms of group size, (2) flexibility with regard to seasonal cycles of harvest and resource use backed up by oral traditions to provide group memory, (3) detailed local environmental knowledge and related skill sets, (4) sharing mechanisms and social networks to provide mutual support and minimize risks, and (5) intercommunity trade. 
The Arctic is an environment in which biological production is relatively low, resources are patchy, and resource availability is unpredictable. These conditions have a profound influence on social organization because adaptive pressures are against large social groupings and permanent settlements in favor of small groups and a high degree of mobility. Thus, traditional Inuit society was generally organized to facilitate the constant grouping and regrouping of economically self-supporting households to maximize the amount of resources obtained and their distribution throughout the group (Freeman 1996). For example, one study of settlement and mobility patterns showed a statistically significant correlation between resource abundance and seasonal preferences for settlement location (Freeman 1967). This is also evident in events such as the hunts for beluga whale on the Mackenzie Delta, where large social groups come together for short periods to increase the number of whales harvested.

In traditional Inuit resource use, there was a great deal of flexibility in seasonal cycles, and mobile groups did not always follow the same sequence of hunting locations or rely on the same complex of resources. They worked with unpredictability, harvesting what was available when it was available. Species could be switched opportunistically; for example, a good spring harvest of ringed seals might compensate for a late snow goose migration. In their seasonal cycle, there was a plan that covered target areas and species, but also a whole repertoire of backup plans in case the primary plan did not work. These plans were based on their accumulated knowledge of factors such as habitat and animal behavior. The most successful (i.e., foodrich) family leaders were those who had the most comprehensive set of backup plans and who could always find an alternative that produced food (Balikci 1968). The Inuit also relied on oral traditions and group memory of past situations to respond to fluctuations in the physical environment and extreme events (Minc 1986).

In conjunction with their seasonal harvest cycles and backup plans, the Inuit had detailed local environmental knowledge and related skill sets. The unpredictable nature of resource availability creates incentives for individuals to master a diversity of hunting and fishing skills and accumulate a detailed knowledge of the various species and the biophysical environment in general. Diversification is well known as a risk-spreading strategy related to uncertainty and surprise (e.g., McCay 1978, Kelly and Adger 2000), and the Inuit tend to be generalists rather than specialists. Although Inuit society normally has a division of labor based on gender, men can sew skins and women can hunt, if necessary. In fact, three Sachs Harbour sisters, who are now community elders, were raised by their mother when she took over their father's role (e.g., hunting seals at the ice hole) after his premature death. Competence on the land (survival skills) is highly valued and allows individuals to exercise a great degree of personal autonomy (Freeman 1996).

Food sharing was very important among the traditional Inuit, as in many aboriginal groups, especially those who were hunter-gatherers. Co-resident social groups among Canadian Inuit bands were small until the 1960 s and 1970s, with winter groups numbering 50 to 100 and summer groups generally comprising fewer than 25 people. When groups consisted of only a dozen or so households, it was possible to share a kill such as a seal or a small whale with the entire community (Freeman 1996). Inuit food sharing often went beyond the immediate group as well, because the Inuit tended to have complex networks of social relationships, and exchanges took place based on these extensive networks. A very high value was attached to sharing: the most socially prestigious families were those who always had food to share. Social networks for sharing are adaptive in terms of providing mutual support and minimizing risks (Sabo 1991).

In many parts of the Arctic, intercommunity trade was important as a means of addressing regional differences in resource availability. Some of these trading partnerships were highly formalized, but they should also be understood as mechanisms for providing mutual support when traveling into the territories of neighboring groups. Trading was as much a symbolic act, intended to establish social relationships between groups and recruit loyal partners as it was an economic transaction (Freeman 1996).

\section{EVALUATING TRADITIONAL ADAPTIVE STRATEGIES}

Human history in the Arctic has been described as a series of adaptations, or a process of sequentially accumulating cultural mechanisms, designed to deal with the characteristics of the environment (Krupnik 1993). To evaluate the resilience of Inuvialuit society in the face of climate change, we first asked which of these five sets of adaptive mechanisms were still 
viable. Second, we tried to determine if there were other response options the Inuvialuit could choose to deal with environmental change.

Inuit society has undergone profound changes since the 1960s and the 1970s, when the people first settled into permanent villages. For this reason, the cultural adaptations that involve mobility and flexible group size are no longer available or relevant. However, the other four clusters of adaptations still seem to be viable. Our analysis in this section is based on observations and interviews in Sachs Harbour, but parts of our discussion are necessarily speculative, because the evaluation of traditional cultural adaptations was not part of our initial research objectives.

The Sachs Harbour case indicates that hunters still make "... dynamic and flexible use of the environment ... " (Krupnik 1993). The flexibility of seasonal cycles of harvest and resource use provides the socialecological resilience needed to cope with increased variability and unpredictability and adapt to change. We infer resilience from those project results that show a diversity of short-term responses to changing patterns of game availability and access. Cultural values in the community of Sachs Harbour that emphasize the appropriateness of harvesting what is available and acting opportunistically no doubt facilitated the observed coping strategies. Likewise, we observed that oral traditions and group memory were used to establish baselines for expected variability. For example, the people recalled the past to make sense of unusual ice years or late freeze-up. In some cases, however, oral history and the elders' memories did not help much. A case in point is the thunder and lightning observed in the 1990s; only two elders had ever experienced this weather phenomenon in their lifetimes, one of them in the 1930s when she was only five years old. Thus, recent occurrences are seen as indicators of environmental change on a larger scale.

A great deal has been written about the loss of detailed knowledge about the local environment and related skill sets. This is only partly true. Some knowledge and skills have obviously been lost, some are being transmitted incompletely, and yet others are new skills (such as the use of snowmobiles) that the older generations did not possess. In this regard, the situation in Sachs Harbour is probably not very different from those of other northern communities in which the transmission and retention of knowledge and skills have been studied systematically. One general finding is that skills tend to be transmitted later in life and incompletely (Ohmagari and Berkes 1997). In the case of Sachs Harbour, even the younger people know about traditional food preservation techniques such as fermented marine mammal meat, and some of them have assisted with the process. However, only a small number of elders had the experience needed to carry out all the steps of the preservation process by themselves; the others did not have sufficient expertise.

A second general finding is that there has been a change in the skill sets and kinds of land-based knowledge held and transmitted. For example, many teenage boys in Sachs Harbour can use guns, but not too many can build snowhouses and snow shelters, which was once universal knowledge. However, those who are often on the land do learn to build snow shelters, because it is an essential survival skill. Thus, some traditional skills that were once universal in Inuvialuit society have become restricted to the relatively few families who are active on the land. This is because learning traditional knowledge and skills requires on-the-land education (Ohmagari and Berkes 1997) or " ... people's practical engagement with the environment ... " (Ingold and Kurttila 2000). As the nature of this practical engagement changes, so does the reservoir of local knowledge. For example, hunters in Sachs Harbour and elsewhere in the Canadian North use GPS units for navigation and safety-a very recently acquired skill. The use of snowmobiles since the 1970s has required a greater degree of knowledge of safe and unsafe ice, because sled dogs can sense dangerous ice, but snowmobiles cannot.

The sharing of food is still very much in evidence in Sachs Harbour, but it remains for the most part within extended family units, or involves providing for elders. Partly because the community is so small and the families are interrelated, just about everyone gets to share some of the food coming in. However, because a relatively small number of hunters now account for most of the fish and game harvest, fewer and fewer people seem to be providing for more and more nonhunters, a potentially nonsustainable situation. This imbalance is being addressed by new forms of reciprocity in which food-rich members of extended families share with cash-rich members, thus bringing wage income and material goods into the sphere of sharing relationships. 
One kind of adaptation that does not seem to have declined at all, and may even have increased, is intercommunity trade. Sachs Harbour has an abundance of snow geese and musk-ox, but a dearth of caribou and beluga whales because it lacks the shallow, rocky bays suitable for hauling and butchering beluga. Therefore, the community exports snow geese and musk-ox to Tuktoyaktuk and Inuvik, and in turn receives beluga products (muktuk, the inner skin of the beluga) and caribou from them. For example, in the fall of 1999, the community of Tuktoyaktuk sent Sachs Harbour one caribou per family. These exchanges are based on norms of generosity (giving without asking), sharing, and generalized reciprocity, not on western rules of economic exchange (Freeman 1996). When the first bowhead whale in decades was landed in Aklavik, Sachs Harbour received a share of that as well.

Because of family connections, Sachs Harbour trades not only with the Inuvialuit communities to the south but also with Holman on Victoria Island to the east. Holman, in turn, trades with or receives food from other communities. For example, during a caribou crisis on Victoria Island in 1992-1993, the Holman Inuit received caribou meat by air freight from relatives in other communities. The Hunters and Trappers Association of neighboring Kugluktuk (Coppermine) held several caribou hunts, the proceeds of which were shipped to Holman and distributed free to elders (Collings 1997). Thus, intercommunity trade is obviously alive and well.

In sum, Inuvialuit adaptive strategies of flexibility of resource use, local environmental knowledge and skills, sharing through social networks, and intercommunity trade are still largely intact. These strategies provide considerable buffering capacity when dealing with perturbations such as climate change. Are there other response options as well for the Inuvialuit that help them cope with environmental change?

\section{NEW INSTITUTIONS AND ADAPTIVE RESPONSE OPTIONS}

Linkages to Inuit regional institutions and government agencies provide potential adaptive response options that were not available to the Inuvialuit in the past. The Inuvialuit Final Agreement of 1984 sets up five joint decision-making bodies dealing with different aspects of the land and the environment. These co- management bodies provide a formal mechanism that allows individual communities to interact with the regional Inuvialuit government, the territorial government, and the federal government when dealing with large-scale problems (Berkes et al. 2001). Such cross-scale linkages, both horizontal (across space) and vertical (across levels of organization), facilitate new kinds of adaptive responses. They also provide communities access to scientific information through co-management bodies such as the Fisheries Joint Management Committee (Fisheries Joint Management Committee 1999).

Figure 1 shows the relationship between space and time scales in the way in which a community such as Sachs Harbour may respond to climate change. It can be seen that responses on the level of the individual and the household operate at scales ranging to a day to a season; these are the coping strategies. Community and regional-level responses, once established at the scale of years and decades, develop over time into adaptive strategies of the kind discussed by Krupnik (1993) and Freeman (1996).

At the lower ends of the space and time scales, the response to environmental feedback is rapid, e.g., hunters mobilize if the snow geese are migrating early. At the higher ends of the scales, responses are mediated by slow variables (Gunderson and Holling 2001), such as cultural values that change slowly. For example, the adaptive strategy of sharing requires the development and reinforcement of cultural values that favor generosity, reciprocity, and communitarianism and discourage hoarding and individualism. A key question for the new adaptive strategy of comanagement is whether it can facilitate or speed up responses to climate change. For example, the polar bear hunt, an important source of employment in Sachs Harbour, is often affected by unreliable sea ice in spring. The sport hunting season is a fixed period, set by the territorial government. Can the season be changed to reflect changing ice conditions? More generally, the question is: how quickly can a community concern (e.g., unreliable ice in the spring) be translated into action at the larger institutional scale, if the local institution (e.g., Hunters Trappers Committee of Sachs Harbour) wants to change the polar bear hunting season to respond to changes in the supply of polar bear resources?

According to John Nagy (personal communication) of the Department of Resources, Wildlife and Economic 
Development (RWED), the community polar bear agreements that RWED and Inuvialuit institutions are presently working on provisions that will allow the communities to adjust their hunting seasons by means of HTC bylaws within the broader Northwest Territories hunting season. These new agreements may be signed off sometime in 2001, giving communities greater flexibility to adjust seasons both for their members and for sport hunters.

Regionally, co-management arrangements have since the $1980 \mathrm{~s}$ provided greater northern aboriginal participation in environmental management. In the western Arctic, the Inuvialuit have joint decisionmaking powers in a range of areas, from fish and wildlife management to protected areas, environmental assessment, and policies governing research on contaminants (Berkes et al. 2001). These powers provide greater local flexibility and response capability in dealing with uncertainties such as climate change. They enable local communities to respond to environmental feedback more quickly, without having to wait for the intervention of distant governments. Interaction with scientists in jointly planned meetings such as the Beaufort Sea Conference (Fisheries Joint Management Committee 1999) provide additional means for learning and self-organization that help to build local adaptive capacity to address environmental management issues at the regional, national, and international levels.

\section{CONCLUSION}

In carrying out place-specific research in Sachs Harbour, we have tried to develop an approach that involves (1) observing and analyzing the actual response of the community to climate change, (2) evaluating these observations in the light of the adaptive strategies known to exist in that society, and (3) using these two streams of thought to generate insights about the resilience of the social-ecological system (the community and its resources) and further response options. One of the insights from this study is the key importance of participatory research in the production of knowledge that is based on social understanding. The research team could not have made much sense of the observations if it did not have the benefit of a planning workshop in which the people of Sachs Harbour indicated what they considered important at the outset of the project; other helpful components were the use of video to capture local observations, repeat visits, multiple feedback of results, and the verification of those results.

Such an approach is consistent with the sustainability science statement of the Friibergh Workshop, which points out that the complex systems problems facing humanity are not adequately addressed by the familiar scientific approach of developing and testing hypotheses. Because of nonlinearity, complexity and long time lags, sustainability science will need to use new methodologies, build upon lessons provided by case studies, and work with the local people to produce knowledge " ... that is both scientifically sound and rooted in social understanding ... " (Friibergh Workshop on Sustainability Science 2000).

Climate change provides a good example of a complex systems problem for which place-specific case studies and participatory methodologies are particularly apt. The effects of change unfold at the local level, and so do adaptive responses, creating opportunities to investigate the dynamics of the two. The Sachs Harbour case is informative in studying how societies adapt to climate change because the Inuvialuit response occurs on multiple scales. One set of responses is short term; these are the coping mechanisms. Because the Inuvialuit are experts at living in highly variable environments, it is not surprising that switching species and adjusting the "where, when, and how" of hunting have enabled them to cope successfully with climate change in the 1990s.

The question of the ability to adapt to further changes brings into focus longer-term adaptations and responses, including the flexibility of seasonal hunting patterns, detailed traditional knowledge of the environment that enables the Inuvialuit to diversify their activities, and inter- and intracommunity sharing networks. Climate change puts these adaptations under stress by making the environment even more variable and thus less predictable. The range and extent of both the short-term and long-term responses define the resilience of the community in the face of change. To the extent that these responses are impaired, the population becomes vulnerable to change (Kelly and Adger 2000).

Climate change at Sachs Harbour, as elsewhere, has not followed a pattern of smooth or gradual change. It has been marked by disruptions due to uncertainty and extreme events. Our research supports the observation that changes in long-term averages are not so important. Rather, it is extreme events that are 
important, " ... events of greater magnitude, especially those which exceed a system's 'absorptive capacity' ..." (Smithers and Smit 1997:135). However, not all extreme events (e.g., thunder and lightning) are dangerous, and not all ecological surprises are negative from the local point of view (e.g., the appearance of Pacific salmon in the Beaufort Sea). The two species of Pacific salmon, observed for the first time in the 1990s by the people of Sachs Harbour and recorded by biologists (Babaluk et al. 2000), and mainland ducks that are now extending their range into the High Arctic both provide a welcome supplement to the Sachs Harbour diet.

Fig. 1. Responding to climate change in Sachs Harbour: the time scale of responses in relation to different social and political scales of organization.

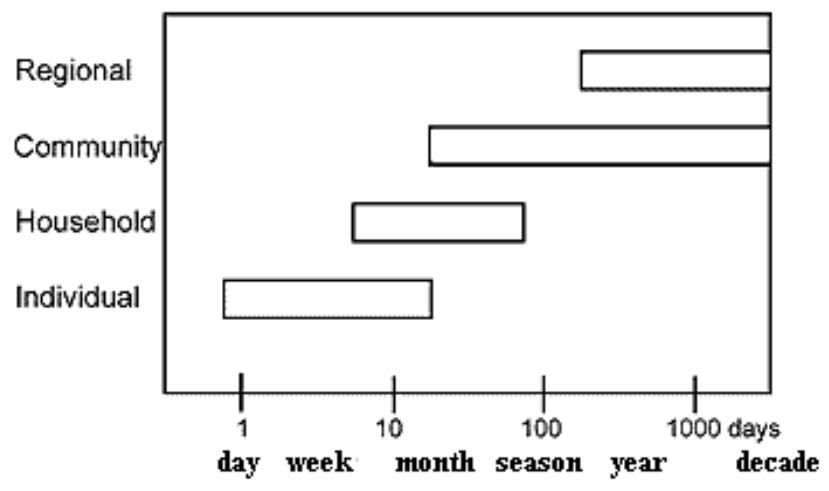

This multiscale approach to studying the system's "absorptive capacity" or resilience is useful in highlighting the fact that coping and adaptive strategies are continuous along the temporal scale (Fig. 1). There is feedback between the various levels of responses to change (household, community, etc.), especially between those that overlap on the temporal scale. Feedback is weaker and slower between the levels at the extremes of the scale in Fig. 1, that is, between the individual/household levels and the levels above the community), which tends to weaken the relationship between them (Levin 1999).

co-management institutions that have been developing since the 1980s have the potential to connect the different levels of the system and speed up feedback among the levels. They can facilitate self-organization and learning; for example, the Inuvialuit and scientists may learn from one another and find ways in which local knowledge may complement science (Fisheries Joint Management Committee 1999, Riedlinger and Berkes 2001). By providing the community with vertical linkages across levels of organization, these co-management arrangements allow community concerns to be transmitted to regional, national, and international levels. New institutional linkages can thus increase the resilience of the social-ecological system by providing for crossscale communication that did not exist before the 1980s, and by increasing the capability for self-organization and the capacity for learning.

Responses to this article can be read online at: http://www.consecol.org/vol5/iss2/art18/responses/index.html

\section{Acknowledgments}

The project was supported by the Walter and Duncan Gordon Foundation, the Arctic Institute of North America (AINA), NSTP, and the Social Sciences and Humanities Research Council of Canada (SSHRC). Parts of this paper are based on DR's report to AINA. We thank the community of Sachs Harbour, and the many wonderful people there, for providing the opportunity to pursue this research, the International Institute for Sustainable Development, and the Inuit Observations of Climate Change project team. We thank John Nagy, Nobuhiro Kishigami and Jem Berkes for their help with the MS.

\section{LITERATURE CITED}

Adger, W. N. 2000. Social and ecological resilience: are they related? Progress in Human Geography 24:347-364.

Adger, W. N., P. M. Kelly, and N. H. Ninh, editors. 2001. Living with environmental change: social vulnerability, adaptation and resilience in Vietnam. Routledge, London, UK.

Babaluk, J. A., J. D. Reist, J. D. Johnson, and L. Johnson. 2000. First records of sockeye (Oncorhynchus nerka) and pink salmon (O. gorbuscha) from Banks Island and other records of Pacific salmon in Northwest Territories, Canada. Arctic 53:161-164.

Balikci, A. 1968. The Netsilik Eskimos: adaptive processes. Pages 72-82 in R. B. Lee and I. DeVore, editors. Man the hunter. Aldine, Chicago, Illinois, USA. 
Berkes, F., and H. Fast. 1996. Aboriginal peoples: the basis for policy-making towards sustainable development. Pages 204-264 in A. Dale and J. B. Robinson, editors. Achieving sustainable development. University of British Columbia Press, Vancouver, British Columbia, Canada.

Berkes, F., and C. Folke, editors. 1998. Linking social and ecological systems: management practices and social mechanisms for building resilience. Cambridge University Press, Cambridge, UK.

Berkes, F., J. Mathias, M. Kislalioglu, and H. Fast. 2001. The Canadian Arctic and the Oceans Act: the development of participatory environmental research and management. Ocean \& Coastal Management 44(3): 451-469.

Collings, P. 1997. The cultural context of wildlife management in the Canadian North. Pages 13-40 in J. McCarter and E. A. Smith, editors. Contested Arctic. University of Washington Press, Seattle, Washington, USA.

Davies, S. 1993. Are coping strategies a cop out? Institute for Development Studies Bulletin 24(4):60-72.

Fast, H., and F. Berkes. 1998. Climate change, northern subsistence and land-based economies. Pages 206-226 in N. Mayer and W. Avis, editors. Canada country study: climate impacts and adaptation. National Cross-Cutting Issues, Volume 8. Environment Canada, Ottawa, Ontario, Canada. Available online at: www.ec.gc.ca/climate/ccs/pdfs/volume8/vol8ch8.pdf.

Fast, H., and J. Mathias. 2000. Directions towards marine conservation in Canada's western Arctic. Ocean \& Coastal Management 34(11): 183-205.

Fisheries Joint Management Committee. 1999. Beaufort Sea 2000: renewable resources for our children; conference summary report, September 15-18, 1999. Fisheries Joint Management Committee, Inuvik, Northwest Territories, Canada. Available online at: http://www.fjmc.ca.

Ford, N. 1999. Communicating climate change from the perspective of local people: a case study from Arctic Canada. Journal of Development Communication 1(11):93108.

Freeman, M. M. R. 1996. Identity, health and social order. Pages 57-71 in M.-L. Foller and L. O. Hansson, editors. Human ecology and health: adaptation to a changing world. Gothenburg University, Gothenburg, Sweden.

Freeman, M. M. R. 1967. An ecological study of the mobility and settlement patterns among the Belcher Island Eskimo. Arctic 20:154-175.
Friibergh Workshop on Sustainability Science. 2000. Sustainability science: statement of the Friibergh Workshop on Sustainability Science, 11-14 October, 2000. Friibergh Manor, Örsundsbro, Sweden.

Gunderson, L. H., and C. S. Holling, editors. 2001. Panarchy: understanding transformations in systems of humans and nature. Island Press, Washington, D.C., USA.

Gunderson L. H., C. S. Holling, and S. S. Light, editors. 1995. Barriers and bridges to the renewal of ecosystems and institutions. Columbia University Press, New York, New York, USA.

Gunn, A., C. C. Shank, and B. McLean. 1991. The history, status and management of muskoxen on Banks Island. Arctic 44:188-195.

Holling, C. S. 1973. Resilience and stability of ecological systems. Annual Review of Ecology and Systematics 4:1-23.

Holling, C. S. 1997. Regional responses to global change. Conservation Ecology 1(2):3. [online] URL: http://www.consecol.org/vol1/iss2/art3.

Ingold, T., and T. Kurttila. 2000. Perceiving the environment in Finnish Lapland. Body \& Society 6:183-196.

Kelly, P. M., and W. N. Adger. 2000. Theory and practice in assessing vulnerability to climate change and facilitating adaptation. Climatic Change 47:325-352.

Krupnik, I. 1993. Arctic adaptations: native whalers and reindeer herders of northern Eurasia.University Press of New England, Hanover, New Hampshire, USA.

Langdon, S. J. 1995. Increments, ranges and thresholds: human population responses to climate change in northern Alaska. Pages 139-154 in D. L. Peterson and D. R. Johnson, editors. Human ecology and climate change: people and resources in the far north. Taylor \& Francis, Washington, D.C., USA.

Levin, S. A. 1999. Fragile dominion: complexity and the commons. Perseus, Reading, Massachusetts, USA.

Maxwell, B. 1997. Responding to global climate change in the Arctic. Canada Country Study: Climate Impacts and Adaptation, Volume 2. Environment Canada, Ottawa, Ontario, Canada. Available online at: www.ec.gc.ca/climate/ccs/volume2.htm.

McCay, B. J. 1978. Systems ecology, people ecology and the anthropology of fishing communities. Human Ecology 6:397-422. 
McIntosh, R. J., J. A. Tainter, and S. K. McIntosh, editors. 2000. The way the wind blows: climate, history and human action. Columbia University Press, New York, New York, USA.

Minc, L. D. 1986. Scarcity and survival: the role of oral tradition in mediating subsistence crises. Journal of Anthropological Archaeology 5:39-113.

Nagy, J. A., N. Larter, M. Branigan, E. McLean, and J. Hines. 2001. co-management plan for caribou, musk-ox, arctic wolves, snow geese and small herbivores on Banks Island. Department of Resources, Wildlife and Economic Development, Inuvik, Northwest Territories, Canada.

Ohmagari, K., and F. Berkes. 1997. Transmission of indigenous knowledge and bush skills among the Western James Bay Cree women of subarctic Canada. Human Ecology 25:197-222.

Resilience Alliance. 2001. Resilience Alliance program description. Available online at: http://www.resalliance.org

Riedlinger, D. 1999. Climate change and the Inuvialuit of Banks Island, NWT: using traditional environmental knowledge to complement Western science. InfoNorth (Arctic) 52(4):430-432.

Riedlinger, D., and F. Berkes. 2001. Contributions of traditional knowledge to understanding climate change in the Canadian Arctic. Polar Record 37: 315-328.

Sabo, G., III. 1991. Long term adaptations among Arctic hunter-gatherers: a case study from southern Baffin Island. Garland, New York, New York, USA.

Singh, N., and V. Titi. 1994. Adaptive strategies of the poor in arid and semi-arid lands: in search of sustainable livelihoods. International Institute for Sustainable Development, Winnipeg, Manitoba, Canada.

Smithers, J., and B. Smit. 1997. Human adaptability to climatic variability and change. Global Environmental Change 7:129-146.

Usher, P. J. 1970. The Bankslanders: economy and ecology of a frontier trapping community. Department of Indian Affairs and Northern Development, Ottawa, Ontario, Canada.

Watson, R. T., M. C. Zinyowera, and R. H. Moss. 1996. Impacts, adaptations and mitigation of climate change: scientific-technical analyses; report of Working Group II to the Second Assessment Report of IPCC. Cambridge University Press, Cambridge, UK.
Wilbanks, T. J., and R. W. Kates. 1999. Global change in local places: how scale matters. Climatic Change 43:601628. 